\title{
The Role of the Teacher-Student Relationship in Promoting English Language Learners' Engagement for Online Learning during the Covid-19 Pandemic
}

\author{
${\text { Eunae } \mathrm{Kim}^{1 *} \text { and Lewinna Aguskin }}^{2}$
}

\author{
${ }^{1}$ Bandung Independent School \\ ${ }^{2}$ Maranatha Christian University \\ *Corresponding author. Email: eunae.kim@bisedu.or.id
}

\begin{abstract}
In one classroom, students bring various motivations to learn English. However, not all motivations directly connect to their engagement in class. Since students' engagement affects their learning and long-term success, it plays a significant role in Second Language Acquisition. Since March 2020, due to COVID-19 Indonesian students and schools have had to go through massive learning changes without being much prepared. This research aims to inquire what factors are influencing the university students' engagement during online learning and study to what extent Teacher-Student Relationship (TSR) influence the engagement of university students during online learning using a qualitative case study method to stress how positive TSR is essential to get through this challenging time. To collect data, the researchers surveyed using the Student Instructor-Relationship Scale (SIRS). They also used open-ended questions, video recordings containing the reflections from 35 students, and interviews from students and teachers. Students' assessments were evaluated to analyze the relationship between TSR and their engagement and performance in class. Results showed that Indonesian students were facing various challenges. It turned out that 13 students who had personal check-ins with the teacher had a positive perception toward the teacher; their engagement was slightly better. Their instructor anxiety was lower than the whole class average. A variety of pedagogical implications are suggested to support students in overcoming the challenges they face, especially during and after the COVID-19 pandemic.
\end{abstract}

Keywords: Engagement, Teacher-Student Relationship (TSR), Second language Acquisition, Covid-19

\section{INTRODUCTION}

COVID-19 has changed the definition of learning. People all around the world had to go through massive transitions due to this newly found virus. Indonesia was not an exception. Since March 9, 2020, a regulation was enacted by the Indonesian Ministry of Education and Culture that all students and teachers should work and study from home [1]. Many teachers had to obtain new online teaching skills through webinars and videos. Meanwhile, students and parents had to figure out how to set up an online learning environment at home. The situation was even more challenging because some communities had suffered from not having a stable internet connection and devices to learn online. After almost a year and a half of online learning, the situation is not much different. Teachers and professors at the university level have witnessed that some students lose their interest and passion for learning while others stay strong.

Students' engagement in online classes has become a crucial and influential aspect indeed. With increased distractions and physical difficulties, students wrestle to find the motivation to attend everyday class. When students have engaged actively in the classroom activities, they can interact with teachers and peers and practice their language skills and achieve their best potential as much as possible. On the other hand, if students do not engage in classroom activities and stay passive in the process of learning, they will not get much out of their learning.

\subsection{The Importance of Teacher-Student Relationship (TSR)}

According to Mercer and Dörnyei [2][P: 14], even though the idea of "engagement" is critical in language learning classrooms, the concept has not been discussed to a great extent in the area of Second Language Acquisition.

Mercer and Dörnyei also discuss various factors that influence student engagement, and one of them is Teacher-Student Rapport. [2] They introduced six principles that teachers should use to build a positive relationship with their learners. Principle one is being approachable. It includes teachers being physically 
present and offering some degree of self-disclosure, willingness to share their personal experiences. [P: 54] Principle two is being empathetic. Teachers can show a good model of displaying empathy towards students to learn how to be empathetic to their peers [P: 55]. Principle three is being responsive to learner individuality. Teachers must believe that all learners are unique and that all learners can learn. Learning should be learner-centered and differentiated according to the levels of learners [P: 56]. Principle four is believing in all your learners. Teachers should have a growth mindset about learners' language learning abilities and have high expectations [P: 57]. Principle five is supporting learner autonomy. Teachers should be facilitators and provide students with more choices and opportunities [P: 59]. Principle six is being passionate about what you do. All these principles demonstrate what kinds of character traits teachers should present to their students [P: 59]. Furthermore, Mercer and Dörnyei continue to discuss how we need to "plan and teach with the quality of our relationship with our students at the forefront of our minds." since it is easy for "teachers to be caught up in the mechanics of teaching" and losing the focus on building relationships [P: 52]. Teachers often focus on delivering what they know to students, lacking time and effort to develop meaningful relationships with their students.

Kermad and Kang (2018) [3] underline that it is the teacher's responsibility to create a supportive and positive classroom environment. They also believe that certain characteristics of a teacher will promote positive TSR effectively. In their research related to the Asian education context, Nikitina and Fukuoka (2009, as cited in Kermad and Kang) [3] explain three social psychology dimensions related to TSR: affective, behavioral, and cognitive. The teacher's characteristics associated with the affective dimension are "interesting, colorful, exciting, imaginative, and trusting" [P: 2]. Regarding the cognitive dimension, the characteristics are "efficient, competent, organized, industrious, and capable" [P: 2]. Then, the behavioral dimension is expressed in the characteristics such as "polite, friendly, pleasant, and patient" [P: 2]. Interestingly, the survey among 100 Malaysian university students revealed the most desirable and least desirable characteristics of a language teacher. It is stated that the most desirable characteristics are "caring/emphatic, patient, friendly, interesting, good teaching skills/ability, cheerful, creative, polite, sincere, and organized." [P: 2] Meanwhile, the least desirable characteristics are "boring, inconsiderate, lack professional skills, unfriendly, emotional, impolite, angry, disorganized, too strict, and bad rapport with students." [P: 2] Thus, the implication of this research for classroom practice is to bridge the gap between teachers and learners by applying student-centered learning in the teaching process.

Hagenauer and Volet (2014) [4] have focused on the importance of the TSR in higher education due to three reasons. First, TSR is critical to minimize the retention rates of university students. Second, TSR is also influential for the affective aspect of university teachers to create a positive relational environment. Third, TSR is significant in promoting the excellent quality of higher education institutions. TSR should be given proportional attention considering that TSR has some significant impacts on the success and satisfaction of the students and the well-being of the university teachers.

Based on his personal experiences, Abrahamson (2011) [5] has explored and practiced various methods of creating and maintaining interpersonal connections between professors and students for more than 35 years. He believes that TSR is developed by mutual sharing of personal experiences, values, beliefs, and course content. Starting from the first day of the class, the professor needs to believe in every student's ability, acknowledge the effort of each student to participate in the class, and promote interpersonal connection with the students. The professors can encourage the students by creating class assignments that allow them to share their own stories, feelings, and perspectives on the course content. Showing continuous positive reinforcement to the students using verbal and non-verbal communication is truly important to create a motivational learning atmosphere for nurturing the connection. Thus, motivating the students to be passionate about the course content and relate it to their lives will be possible when the relationship has become an integral part of the classroom environment. When the students recognize their professors' intellectual and emotional empathy, they will develop their passion and ownership of learning.

\subsection{Studies of the challenges of online learning and TSR in Indonesia}

Several studies focused on the challenges of online learning and the importance of the TSR in Indonesia. First, Fatoni, et al. (2020) [6] investigated the benefits, limitations, and suggestions of studying online for 100 students in five private universities in Indonesia. The result reveals that network instability has been the most problematic situation that interfered the online learning. In addition, the lack of direct interaction and concentration has been very challenging. On the other hand, online learning has made it possible for the students to have a comfortable, educational environment; they could listen anytime and anywhere without being limited by time or space. The suggestions for online learning are improving network stability and activating class interaction.

Second, in their research Padmo, D et al. (2020) [1] have explored the implementation of online learning during the pandemic among 828 respondents who are lecturers and students from various universities in Indonesia. The study indicated that the transition to online learning was not well organized, specifically regarding learning methods and strategies. It is suggested that the implementation of online learning should be varied by combining online synchronous and asynchronous learning and blended learning.

Third, Syahabuddin, Fhonna, and Maghfirah (2020) [7] have stated the importance of the TSR and 
shown its influence on the teaching and learning process. Understanding the needs and beliefs of the students is influential in motivating the students because a positive relationship will create a personal connection between teacher and students, which results in positive outcomes at school. The participants of this study are 14 teachers and 43 students from two junior high schools in Aceh. Based on the interview with teachers and the result of the student questionnaire, the study shows a significant correlation between the TSR and the teaching-learning process in the first school. Still, there is no significant correlation in the second school. The students found it challenging to interact with the teachers because they were shy and afraid of making mistakes. They felt hesitant to communicate with the senior teachers and felt neglected by the teachers.

Fourth, Pasaribu T.A. and Dewi, N (2021) [8] have researched to explore the EFL students' voices during online learning in one Indonesian university. They expressed the changes they have experienced during the pandemic, the things they have learned and their ways of learning, their feelings of online learning, and their test/exam preparation. After investigating twenty student reflections regarding their feelings and opinions of online courses, the researchers discovered that online learning had been a meaningful and personal experience for them. The value of learning has become a new focus in dealing with difficulties. Social engagement and learner autonomy have been utilized more regularly. As for the teachers, their awareness of using various lexical choices to maintain positive rapport has been explored more deeply.

There have been several studies regarding the challenges of online learning and the importance of the TSR. Nonetheless, to the best of our knowledge, there is little research on the TSR among university students in Indonesia during online learning due to the pandemic. TSR is one factor that is critical for student engagement but, "Teacher-Student Relationship in higher education has been less comprehensively and less systematically examined by researchers. There are far fewer studies on TSR in higher education than in the school context" (Hagenauer \& Volet, 2014) [4]P: [371]. Thus, this research aims to fill the gap of investigating the students' perceptions regarding the online learning challenges and their attitude related to TSR. This study explores various challenges and factors that university students face, which influence their engagement in online learning, and to discover to what extent the TSR affects the engagement of university students during online learning.

\section{METHODS}

The participants of this study are 35 undergraduate students of a private university in Indonesia. Their ages are between 19-22 years old. A method of qualitative approach is conducted to answer the research questions. An online questionnaire was used to survey students about their experiences and perceptions towards online learning and their relationship with their instructor to collect data. The survey was adapted from the original
Student Instructor-Relationship Scale (SIRS), which contained 36 questions [9], with five open-ended questions added. The result was measured in percentage and compared variables to evaluate the correlations of formative and summative assessment scores, the connectedness of their instructor, and anxiety toward the instructor to point out any specific correlations. Also, students answered three open-ended questions regarding their overall online learning experiences and personal challenges by recording reflections on Flipgrid. As a tool to measure students' engagement, the researchers chose four formative and summative assessments scores. Due to various difficulties, it was not fair to observe students' engagement in a live zoom meeting objectively, so the researchers have decided to use formative and summative assessments to gauge their engagement. Student answers from assessments and teacher interviews were used to understand the history of TSR in class.

\section{RESULT AND DISCUSSION}

\subsection{Challenges faced by students in the online context}

The data is based on the students' reflections regarding the challenges during online learning. The results indicate that from 29 participants, $21(72,4 \%)$ students mentioned that the internet connection was the most complex challenge for them. Many felt that it was something that they could not control. Student A was in the middle of exams, and she lost the internet connection, and she could not submit her test. Student B felt nervous when her teacher asked her questions, and her teacher and peers could not understand her answers well due to internet issues. Student C got kicked out of the Zoom meeting often, so he could not follow the teacher's directions or teachings well, and that caused him to feel frustrated in class. To make sure their internet connection is stable, some students had to buy extra plans on their phones as a backup. When it rains, teachers and students anticipate that there will be problems online.

Moreover, $9(31.03 \%)$ students experienced various kinds of distractions during class. Student D felt distracted because of social media and other apps on the phone. Whenever she got notifications, she would check her phone or play games while listening to the lecture, which could cause her not to get engaged in full in class.

Furthermore, $9(31.03 \%)$ students felt less motivated to join online classes. Student E shared that since she lost her routine to be ready for her class in the morning, she would stay in bed and wake up late and not have a solid motivation to join the class. Student F also mentioned that waking up 5 minutes before class makes him feel exhausted and tired, not wanting to engage in class conversations. Student $G$ felt fewer interactions in the online course, so class content seems more complicated than the face-to-face classroom, and it is hard to be excited about learning.

In addition, $4(13,79 \%)$ students shared that it was hard to create a physical environment for studying. They do not have a quiet place to study where they can feel comfortable engaging in class. Student $\mathrm{H}$ confessed that her family was the problem. Since she has a big family 
and they all stay at home while she is in class, family conversations and their activities can distract her.

The findings are similar to the study of Fatoni et al. (2020) [6] related to the challenges of online learning for university students. The most problematic situations are related to the internet connection, distraction, and motivation. Both studies confirm that having a reliable and stable internet connection, overcoming distractions, and maintaining motivation during online learning are major concerns for university students.

\subsection{Correlations between TSR and the engagement of students}

Regarding the second research question, this part shows the attitudes of students based on the online TSR questionnaire related to the closeness and anxiety with the instructor. Students have answered 36 questions about their perceptions toward the teacher on a scale of $0-5,0$ indicating strongly disagree, and 5 indicating strongly agree. The scores were calculated according to the scoring section written by Creasy et al. [9] After calculating Instructor Connectedness and Instructor Anxiety scores, the numbers were converted to percentages to show the consistency and compare them easily with the student's assessment scores.

Students' engagement was evident in formative and summative assignments since two of the works were individual online quizzes, and the rest were group assignments. The individual quizzes are to check the understanding of the students regarding film and grammar teaching techniques. The group assignments were the projects to create a short video and specific language skills lesson plans. The teacher could witness their engagement by evaluating and observing the performance and cooperation of each student.
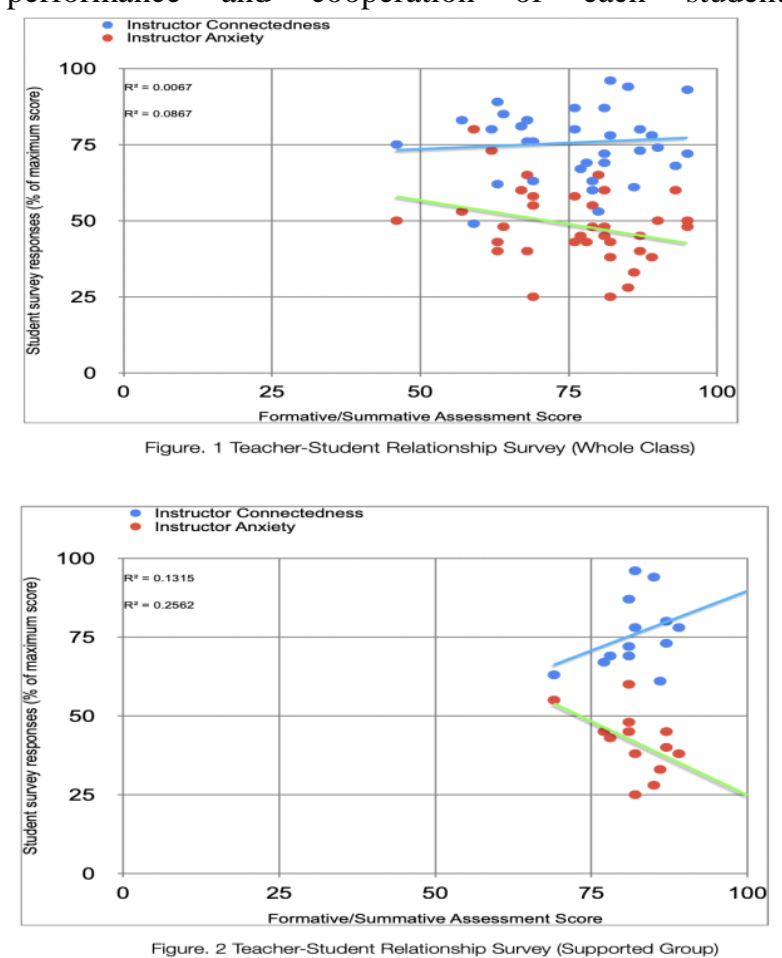

Figure 1 explains the correlations between Instructor Connectedness, Anxiety, and students' engagement as a whole class, while Figure 2 is for a group of 13 students who received extra support from the teacher. As figure 1 suggests, there is no significant correlation between instructor anxiety, connectedness, and students' performances in class as a whole. Due to the limited number of samples, this survey does not prove the direct relationship between TSR and students' engagement in a quantitative approach. However, Figure 2 shows that as higher instructor connectedness score gets, the assessment score increases. As the lower the anxiety goes, the assessment score rises. It means that students with higher connectedness and lower anxiety toward the teacher likely engage better in class. The survey was used to gather data to connect the data to personal stories and comments about the instructor to examine how TSR impacted students' engagement.

\subsection{The benefits of having regular personal check-ins to build connections}

As an academic adviser, the teacher spent time getting to know thirteen students outside of the classroom. In one semester, the teacher had a virtual meeting twice with the students; before the Mid-Term exam weeks and before the End-of-semester exam weeks. Based on the scheduled time, the students could sign up for the meeting individually or in pairs with their peers. They could share their academic and nonacademic concerns such as the progress of the study, exam preparation, learning difficulties, the challenges of studying online, their daily activities, their family conditions, or other issues. The teacher found it essential to talk with the students and see their faces on the screen to let them express their lives and make sure they stayed healthy during the ongoing semester. Besides having virtual meetings, the teacher and the students kept communication open by having a Line Chat Group. The teacher could share important information and stay connected with the students. In addition, the teacher wanted to be approachable and accessible so that the students could use personal chat to communicate their questions or concerns.

Through this research, several benefits of regular check-ins for students were observed. First, students who got extra support from the teacher show higher engagement in class and low anxiety toward the teacher. It was interesting to see that out of 11 students who scored top $30 \%$ of the class, 7 students were from the personal check-in group. The average class assessment score was 76 , but the average supported group score was 82 , which was higher than the class score as a whole. The average score of connectedness was the same. (76) For Instructor anxiety, the average group score was 41 , when the class average was 49 .

Second, the researchers could find a positive perception of the teacher from the learners who were in the supported group. When students were asked to reflect on the Ron Clark Story film and shared who were the memorable or inspiring teachers in their lives, some 
students from the supported group shared that the teacher is their role model for several reasons.

Student A: "We always feel safe in her subjects because she always encourages us no matter what our result is. When we have finished an assignment, she always tells us that she is proud of us by telling us that our job is wonderful, creative, amazing, etc., and it really motivates us more to do the best we can. Even if we got an unsatisfying result, she still told us that we could and will do better and encouraged us with kind words, decreasing our stress. She really inspired us to be patient, warm and always encourage and motivate other people like college friends, family, etc. If someday some of us become a teacher, the teacher will always be our model in teaching our students with patience, warmth, and not forget always to encourage the students."

Student B: "The reason why the teacher is a memorable lecturer for us is that she is so caring and very supportive to us. She always encouraged us to do our very best in every assignment. She always answered every question that we had patiently. Honestly, we really need someone supportive like her."

Based on the students' reflections, it can be seen that when students felt the teacher was always ready to help them and support them, they could feel comfortable sharing their struggles with the teacher.

Third, the researchers found that many of the students from the supported group perceived the online class positively. As stated by some students:

Student C:"I feel like the teacher really helped me a lot during these times."

Student D: "Teacher always welcomes students whenever students need something."

Student E: "The instructor always encourages us to ask them a question if there are difficulties" the teacher always answers clearly and is very enthusiastic about helping me."

Student F: "I can contact the lecturer and ask for feedback more easily."

Student G: "I could just Line my lecturer whenever I have questions about this particular subject."

Amid complex transitions and challenges, the teacher made an effort to be available for students, and students could benefit from the teacher's action. The teacher was enthusiastic about her role and stayed positive, showing a good attitude and a role model.

\subsection{Teacher's perspective regarding the benefits of personal check-ins with students}

Having personal check-ins with the students has had a positive impact on the teacher. As an academic advisor, the teacher could build personal connections with the students and feel supported by the enthusiasm and positive responses of the students in the learning process. The fact that online teaching was exhausting for the teacher cannot be denied. However, observing the positive responses of the students was encouraging for the teacher. As a class instructor, the teacher also made the best use of a Telegram chat group with the leaders of groups and Google Classroom for all the students. The teacher wanted to open the communication for each group as they worked on several class assignments and final projects in groups. Some important information can be shared quickly and directly in the Telegram group. Also, all students had access to communicate with the teacher by using Google Classroom private chat. The teacher encouraged the students not to hesitate to ask questions whenever they have any questions related to group tasks or projects. Responding to the questions from the students was also inspiring for the teacher because it showed how the students were willing to do their best in doing their tasks and projects.

A relationship is never one way. When teachers get positive or negative feedback from the students, they can gain knowledge of the students, their challenges and it helps them to explore ways to support their students properly. Also, teachers value positive reactions from the students feeling validated and appreciated of what they are doing to be motivated to teach better.

Shortly, the results of this study regarding TSR are in line with the study of Mercer and Dörnyei [2], Kermad and Kang [3], and Abrahamson [5]. Mercer and Dörnyei [2] discussed the six principles of building TeacherStudent Rapport. From the survey, many similar qualities of a teacher from the six principles were observed. Students' appreciation of the teacher who showed effort in connection with students demonstrated that the teacher was approachable, empathetic, believing in all learners, passionate about the teacher's role.

Similar to the study of Kermad and Kang [3] related to TSR, the finding of this study indicates that the teacher has shown the effort to create a supportive and positive learning environment for the students and bridge the gap between teachers and learners by applying PBL in the learning process. In addition, the teacher has also demonstrated positive characteristics to promote TSR, especially in behavioral aspects such as patient, friendly, pleasant, and patient.

This study is also consistent with the study of Abrahamson [5], which investigated various ways of developing interpersonal connections between professors and students. The teacher has applied some practical strategies such as appreciating each student's effort in the class with positive compliments, creating tasks that enable them to share their own stories and feelings in Padlet, and motivate them to be enthusiastic with the materials. 


\section{PEDAGOGICAL IMPLICATIONS}

The discussion related to some pedagogical implications to accommodate students' needs when they face difficulties studying online will be elaborated in this part.

\subsection{Use self-assessment tools to evaluate their current teaching practices}

Change starts by acknowledging possibilities for growth. Teacher Self-Assessment created by Center on Great Teachers and Leaders [10] introduces this practical tool which can be used to evaluate how comfortable teachers are with their leadership skills and how they can grow. The first domain is about collaboration and communication. It shows fundamental skills and advanced skills when connecting to students. There are areas like "Developing positive relationships and trust," "Listening skills." Teachers also can assess themselves using the six principles of teachers who are willing to develop Teacher-Student Rapport introduced by Mercer and Dörnyei [2].

Teachers can ask themselves these questions while reflecting on their class. The examples are as following: What are the areas of growth as a teacher? Am I judging students by their performance only or caring to know what is going on in their lives? Are students comfortable enough to reach out to me? What can I do to make myself approachable to students? How can I manage time so that I can meet students and hear their needs? What are practical ways to meet students' needs?

\subsection{Build rapport with students}

This research suggests that students who received more support from teachers engage better in classroom activities. It can be overwhelming to think that teachers should make special time to connect with students because preparing materials for online teaching can be time-consuming. Dörnyei (2001) [2] introduced effective small gestures to get students' attention, including:

Greet students and remember their names, learn something unique about each student and occasionally mention it to them, ask them about their hobbies and lives outside of school, recognize birthdays, include personal topics and examples about students in discussing content matters, and send notes/homework to absent students.

[2, P: 56]

As the teacher did in this research, teachers can set virtual office hours to meet students individually or in groups to provide time to share beyond their academic struggles. Also, teachers can create a virtual group using messengers like WhatsApp, Line, or Google Classroom where students can easily access. The researchers found one student who scored low in teacher connectedness, high teacher anxiety, and low engagement. According to the teacher interview, the student was not opening up well and showed low selfesteem. Teachers may have this kind of student in their classes. Teachers should try to understand where those students are coming from and make themselves available to build trust with them. By understanding their backstories, circumstances, teachers can find ways to accommodate students' needs.

\subsection{Utilize various method to deliver learning materials to students}

Despite the challenges of having online learning and teaching, there are some ways to help the students understand the learning materials and enjoy the learning process. Using Project-Based learning (PBL) for summative assessment is one option. The students worked in a small group to create a storytelling video and a video of a concept of teaching. They could work together and support one another to finish the project.

In addition, the use of PBL supported the implementation of student-centered learning where the students could discover and learn the materials in a meaningful way where the role of the teacher is to become the facilitator and organizer. For creating formative assessment, the teacher could use Padlet, Kahoot, or learning applications in the website learningapps.org. By using Padlet, the students could display their reflective works, give comments to each other's perspectives, and read the comments from the teacher and other students. Using Kahoot and a learning application, the teacher could design some quizzes or engaging online exercises related to the materials to check the students' understanding. The students had virtual Guest Speaking sessions to meet virtually and learn new things from other competent people to deal with physical distances. In addition, the students had a virtual school observation and teacher interview to observe the online process of learning in an elementary school so that they learned some insights related to the principles of teaching practice from the school teachers.

\subsection{Let students be the owners of their own learning}

To support students with their engagement in class, teachers need to design a class to get their attention, spark their interest and help them to find connections and meaning in their life. It's not helping to say, "Focus!" but students need reasons why they should focus. Mercer and Dörnyei [2] stress that teachers should treat "learners as partners in their education."

Treating learners as partners in their own learning means teachers and institutions showing respect and trust to the learners, and also giving them the power and opportunities to take responsibility and direct their own learning within the bounds of the contextual constraints. Engagement is about action and so learners benefit when they are directing that action in ways that are authentic, meaningful and purposeful. [P: 164]

Teachers should try to understand their students when designing class activities. Mercer and Dörnyei (2020) discuss that teachers should "identify five core areas: the participants' needs, preferences, wants, current performance and contextual conditions" [102]. That is 
why TSR should be at the center of education. If teachers fail to identify those areas in planning teaching materials, students will feel bored and not motivated to participate in classroom activities.

\section{CONCLUSION}

There are many doctors, but few care about their patients. There are many teachers, but few care about their student's well-being. People cannot answer quickly how long the Covid-19 pandemic will last. The situation seems like it will stay like this longer than people expected. That is why students need teachers who genuinely care about their well-being, problems, and challenges. Teachers should look further than the surface for students' engagement levels and their performances in class to gain insights into supporting them effectively. PJ Caposey (2014) said, "Great teachers focus not on compliance, but on connections and relationships" [11] [P: 20]

Despite the significant findings, there are several limitations of this research. The hardest part of this research was how to measure actual engagement in class. The researchers realized that many more factors should be considered when measuring engagement in class. This class is divided into synchronous and asynchronous activities. Due to internet connection, many students used their cellphones and tablets to participate in class for synchronous Zoom meetings. So it was not fair to measure students' engagement objectively. Therefore, the researchers have decided to use formative and summative assessments since students were participating through various forms. However, to measure engagement in ELL settings, individual English competency should be considered because some students with low competency levels may seem low in engagement. The silent period can also affect students' engagement in class. Also, Indonesian cultural aspects should be reviewed. The researchers found out that seven students with a high level of connectedness (more than $80 \%$ ) showed relatively high anxiety (more than 50\%). Further research is recommended to explore the relationship between the hierarchy culture of Indonesian students towards teachers, teacher anxiety, and students' engagement in class. Also, what are the factors stopping students to be connected to teachers and practical skills that are effective to connect with challenging students can be explored further.

\section{ACKNOWLEDGMENTS}

The authors would like to express their gratitude to the students and the teacher as the subjects of this research.

\section{REFERENCES}

[1] D. Padmo, L. Sri Ardiasih, and O. Idrus. Online Learning during the COVID-19 Pandemic and its Effect on Future Education in Indonesia, The Impact Of COVID19 on the International Education System, 2020: 71-86.
[2] S. Mercer and Z. Dörnyei, Engaging Language Learners in Contemporary Classrooms. Cambridge: Cambridge University Press, 2020.

[3] A. Kermad and O. Kang, Teacher-student Relationships. Wiley Online Library, The TESOL Encyclopedia of English Language Teaching, 2018: 1-6. Available: https://onlinelibrary.wiley.com/doi/10.1002/978111 8784235.eelt0146. .

[4] G. Hagenauer and S. E. Volet, Teacher-student Relationship at University: An important yet Underresearched field, Oxford Review of Education, 2014, 40 (3): 370-388..

[5] C. E. Abrahamson, Methodologies for Motivating Student Learning through Personal Connections.," Forum on Public Policy Online, 30-Nov-2010. [Online]. Available: https://eric.ed.gov/?id=EJ969845. [Accessed: 11Oct-2021].

[6] F. Fatoni , N. Arifiati, E. Nurkhayati, E. Nurdiawati, Fidziah, G. Pamungkas, S. Adha, Irawan, A. Purwanto, O. Julyanto, and E. Azizi, "University students online learning system during Covid-19 pandemic: Advantages, constraints and solutions," Researchgate, 2020. [Online]. Available: https://www.researchgate.net/publication/34843032 1_University_students_online_learning_system_dur ing_Covid-

19_pandemic_Advantages_constraints_and_solutio ns. [Accessed: 14-Oct-2021].

[7] K. Syahabuddin, R. Fhonna, and U. Maghfirah. Teacher-student Relationships: An Influence on the English Teaching-learning Process," Studies in English Language and Education, 2020, 7 (2):393406.

[8] T. A. Pasaribu and N. Dewi, "Indonesian EFL students' voices on online learning during COVID19 through appraisal analysis," ResearchGate, 2021. [Online]. Available: https://www.researchgate.net/publication/34880565 0_Indonesian_EFL_students'_voices_on_online_lea rning_during_COVID-

19_through_appraisal_analysis. [Accessed: 14-Oct2021].

[9] G. Creasey, P. Jarvis, and E. Knapcik, A measure to Assess Student-instructor Relationships, International Journal for the Scholarship of Teaching and Learning, 2009, 3(2): 1-10.

[10] American Institute for Research, Teacher Leadership Teacher Self-assessment Tool, Center on Great Teachers \& Leaders. [Online]. Available: https://compcenternetwork.org/sites/default/files/ar chive/TeacherLeadership_TeacherSelfAssessment.pdf. [Accessed: 11-Oct-2021].

[11] L. Ferlazzo, Response: Great Teachers Focus on Connections \& Relationships (opinion), Education Week, 05-Mar-2021.[Online]. Available: https://www.edweek.org/teaching-learning/opinionresponse-great-teachers-focus-on-connectionsrelationships/2014/03. [Accessed: 11-Oct-2021]. 